\title{
DISLOCATION OF THE PERONEAL TENDONS WITH MARGINAL FRACTURE OF THE LATERAL MALLEOLUS
}

\author{
SePp Murr, Zürs, Austria
}

Forward displacement of the peroneal tendons from the groove behind the lateral malleolus is not an uncommon injury, but there have been few references to it in the English literature. A sudden strain at the moment when the muscles are tense causes tightening of the peroneal tendons which snaps the peroneal retinaculum and allows the tendons to dislocate from the groove behind the lateral malleolus. Bonnin (1950) suggested that the straining force occurred while the foot was plantar-flexed and everted; but Watson-Jones (1940) believed that the injury occurred from forced dorsiflexion of the ankle, and he reported an operation to prevent recurrent dislocation of the tendons by deepening the groove behind the malleolus.

The injury is often sustained while ski-ing. In the winter of $1958 \mathrm{I}$ treated seven patients with acute dislocation of the peroneal tendons; and there can be no doubt that it occurs from forced dorsiflexion of the ankle joint. The ski-tip dives in and becomes fixed in the snow, the patient being thrown forwards.

The first report of this injury was by Allen in 1895 in the British Medical Journal, in which he reported successful treatment by strapping the ankle for three weeks. Jones (1932) described a method of repair by operation, but conservative treatment by immobilisation in adhesive strapping or plaster was accepted by Watson-Jones (1940), Hauser (1950) and Whitman (1930). Muralt (1956) advised operative repair in recurrent cases.

This paper records three patients in whom forward dislocation of the peroneal tendons occurred with marginal fractures of the lateral malleolus. No report of this condition has been found in the literature over the past thirty years.

\section{CASE REPORTS}

Case 1-A man aged thirty, in good general health, was unable to walk because of pain in his right ankle which he had injured in a manner probably similar to that described above. Clinical examination showed considerable swelling of the right lateral malleolus, which was tender, and over which a loose piece of bone could be felt and moved under the skin. There was tenderness over the calcaneo-fibular ligament, in which pain was produced on forcibly inverting the foot.

The radiograph (Fig. 1) showed quite clearly that a small chip of bone had been broken off the lateral malleolus, with two smaller flakes lying below and between the tip of the lateral malleolus and the talus.

At this stage the diagnosis appeared to be one of torn ligaments with flake fractures; but further clinical examination revealed-not without difficulty-that the peroneal tendons were dislocated forwards and that they were lying in front of the loose chip of bone.

Reduction of both the peroneal tendons and the loose chip of bone was easy, but not stable; the tendons snapped back to the dislocated position immediately the pressure of the fingers was withdrawn, and the fragment of bone, although freely mobile, would not stay in what appeared to be its anatomical position.

Operation-Under local anaesthesia a straight incision was made over the lower fibula and lateral malleolus. A large haematoma was cleared from around the peroneal tendons to reveal that the fractured chip of bone-one to one and a half centimetres in length - was in fact the anterior rim of the groove on the posterior surface of the lateral malleolus in which the peroneal tendons are normally contained. Posteriorly the chip was still attached to the peroneal retinaculum 
and, opening like a door, had allowed the peroneal tendons to lie between the raw surfaces of the chip of bone and the lateral malleolus. The peroneal tendons were held reduced while the chip was sutured into place after suitable drill holes had been made in both it and the lateral malleolus, after which bone and tendons appeared stable. The calcaneo-fibular ligament was repaired (Fig. 2).

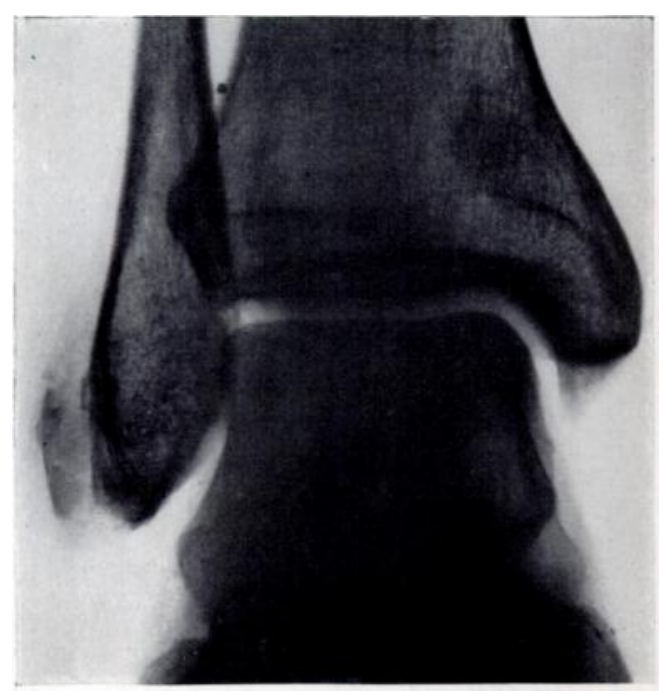

FIG. 1

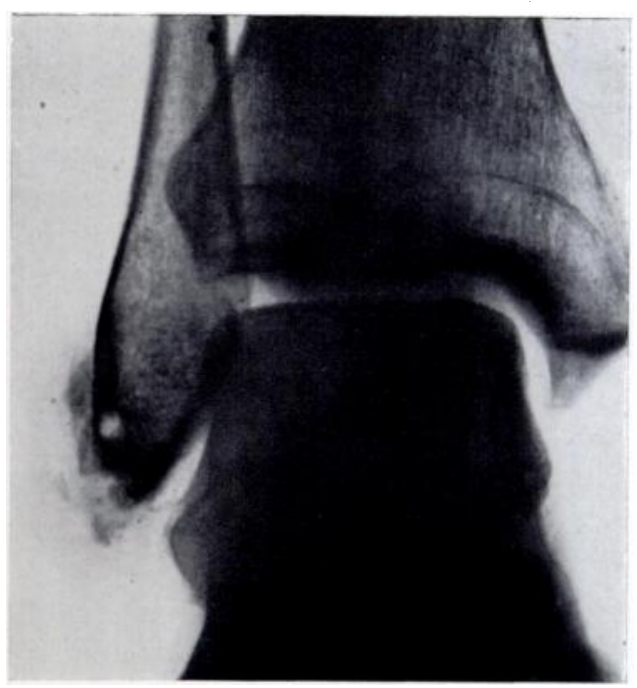

Fig. 2

Case 1. Figure 1-Before operation. Figure 2-After operation.

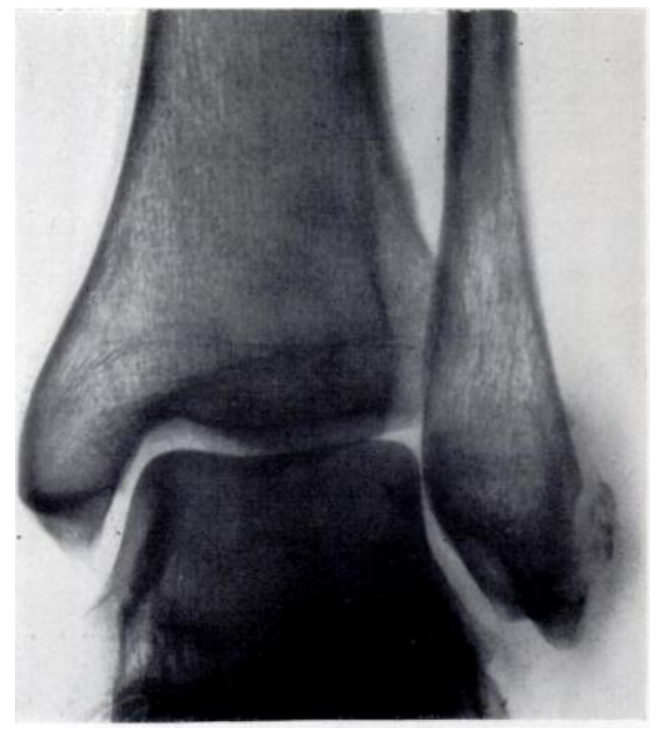

FIG. 3

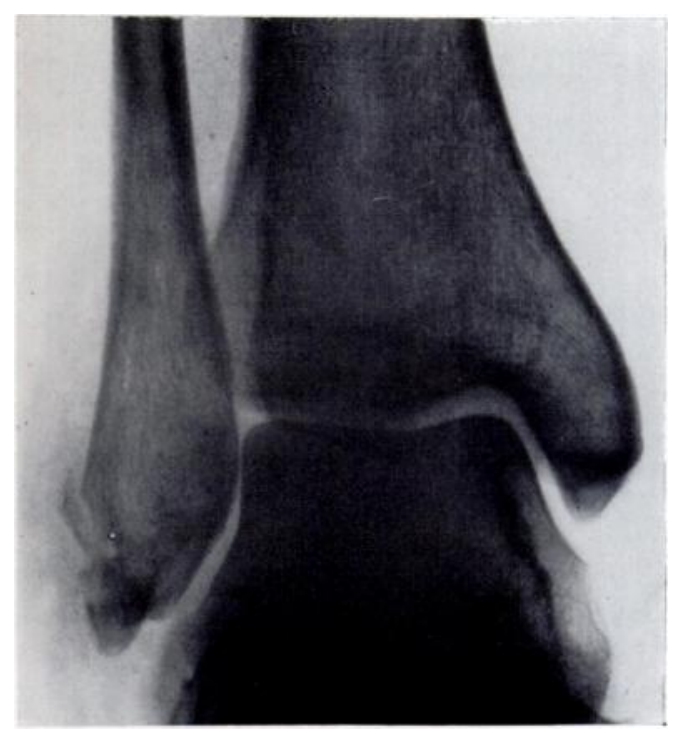

FIG. 4

Figure 3-Case 2. Figure 4-Case 3.

Other cases-Subsequently during the same season two other patients were seen. Case 2 was like Case 1 (Fig. 3), but in Case 3 the patient sustained a bimalleolar fracture (Fig. 4). It was not until seven weeks later, when the patient was walking out of plaster and with the fractures united, that she complained of pain over the lateral malleolus, worse on inversion. Examination gave the same findings as before, with the loose flake of bone and the dislocated tendons. Operation was performed successfully as in the other two cases. 
Results-All three patients returned to ski-ing and have remained free of symptoms. The patient in Case 1 was seen a year after operation and had no residual symptoms, no swelling and no limitation of ankle movements.

\section{DISCUSSION}

This condition could easily be misdiagnosed as a sprained ankle, especially if there were some delay with swelling of the lateral malleolus and if the significance of the radiographic changes were not appreciated.

Once the diagnosis is made operation is indicated because it is simple, quick and reliable. Conservative treatment does not appear possible and should not be attempted, because there is no way in which the peroneal tendons can be held reduced while the fracture unites.

\section{SUMMARY}

1. Three patients are described in whom forward dislocation of the peroneal tendons was associated with a chip fracture of the lateral malleolus and forward dislocation of the tendons through the fracture.

2. This injury differs from the more usual simple anterior dislocation of the peroneal tendons in which rupture of the superior peroneal retinaculum allows the dislocation to occur. 3. A simple operation is described which succeeded in holding reduced the dislocated tendons by suturing the fractured small chip of bone back to the lateral malleolus.

Since this paper was submitted six further patients with this condition have been seen, four of whom have been operated upon. It is too early yet to give the results in these cases.

\section{REFERENCES}

Allaria, A., and Franz, A. (1953): La lussazione traumatica dei tendini dei muscoli peronei laterali. Minerva Ortopedica, 4, 203.

Allen, W. (1895): Dislocation of Peroneus Longus Tendon. British Medical Journal, ii, 1,161.

Bonnin, J. G. (1950): Injuries to the Ankle. London: William Heinemann Medical Books Ltd.

Bragard, K. (1934): Bandage gegen Luxation der Peronealsehnen. Münchener Medizinische Wochenschrift, 81, 2,008.

Hauser, E. D. W. (1950): Diseases of the Foot. Second edition. Philadelphia and London: W. B. Saunders Company.

Jones, E. (1932): Operative Treatment for Chronic Dislocation of the Peroneal Tendons. Journal of Bone and Joint Surgery, 14, 574.

Lohe, R. (1934): Die gewohnheitsmässige Peronealsehnenluxation und ihre operative Beseitigung. Zentralblatt für Chirurgie, 61, 1,154.

Muralt, R. H. v. (1956): Luxation der Peronäalsehnen. Zeitschrift für Orthopädie, 87, 263.

Richard, M. (1930): Über Sehnenluxationen. Deutsche Zeitschrift für Chirurgie, 226, 156.

Romanus, R. (1947): Luxatio tendinum peroneorum. Nordisk Medicin, 36, 2,407.

SChiLdt, E. (1947): Luxatio tendinum peroneorum. Nordisk Medicin, 34, 837.

Volkmann, J. (1937): Zur Pathologie und Behandlung der Peroneussehnenluxation. Archiv fïr Orthopädische und Unfall-Chirurgie, 38, 262.

Watson-Jones, R. (1940): Fractures and Other Bone and Joint Injuries. Edinburgh: E. \& S. Livingstone.

Whitman, R. (1930): A Treatise on Orthopaedic Surgery. Ninth edition. London: Henry Kimpton. 